Open Access

Research Article
Res. Agric. Livest. Fish. Vol. 2, No. 3, December 2015: 459-464

\title{
PREVALENCE OF CANINE PARVO VIRUS INFECTION IN STREET DOGS USING RAPID ANTIGEN DETECTION KIT
}

\author{
Faizul Wasima Nahat, Md. Siddiqur Rahman, Roma Rani Sarker, Md. Kumrul \\ Hassan, AKM Zeaul Hasan, Layla Akter and M Ariful Islam*
}

Department of Medicine, Faculty of Veterinary Science, Bangladesh Agricultural University, Mymensingh-2202, Bangladesh

*Corresponding author: M Ariful Islam; E-mail: maislam77@gmail.com

\section{ARTICLE INFO ABSTRACT}

\section{Received}

23.11.2015

Accepted

10.12.2015

Online

21.12.2015

Key words

Canine parvovirus

Street dog RapiGEN

Ag. Test Kit

Prevalence

Mymensingh
Canine parvovirus is one of the most common infectious diseases of dogs. A study was carried out to diagnose the infection of canine parvovirus in street dogs from different places of Mymensingh Town. Rectal samples were collected from January to April, 2015. A total of 114 rectal swabs were collected conveniently from street dogs of Mymensingh. The samples were diagnosed using RapiGEN Canine Parvo Virus Ag Test Kit. The association of CPV infection with demographic variables was assessed by Chisquare test. The overall prevalence of CPV was $32.0 \%$ in dogs. The prevalence of parvovirus infection was found to be significantly higher in puppies and 6 months of age $(58.3 \%)$ than those $>24$ months of age $(p=0.005)$. The prevalence of canine parvovirus infection also varied significantly in different study area $(p=0.003)$. The prevalence of canine parvovirus infection was higher in male $(34.4 \%)$ than that in female $(30.2 \%)$ but it was not statistically significant.

To cite this article: Nahat F W, M S Rahman, R R Sarker, M K Hassan, A K M Zeaul Hasan, Layla Akter and M A Islam, 2015. Prevalence of canine parvo virus infection in street dogs using rapid antigen detection kit. Res. Agric. Livest. Fish. 2 (3): 459-464.

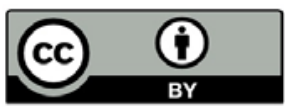

This is an open access article licensed under the terms of the Creative Commons Attribution 4.0 International License

www.agroaid-bd.org/ralf, E-mail: editor.ralf@gmail.com 


\section{INTRODUCTION}

Canine parvovirus (CPV) enteritis is one of the most common infectious diseases and important viral cause of diarrhea in dogs. CPV infection is a relatively new disease that initially emerged in 1978 to a native canine population and spread rapidly with high morbidity (100\%) and mortality (10\%) (Shackelton et al., 2005; Schoeman et al., 2013). Parvovirus enteritis is a highly contagious disease which is spread by the fecal material of affected animals. It is a serious disease, and can vary from mild to over $90 \%$ fatal if untreated. The disease if not properly treated (Parrish, 1995). It causes vomiting, diarrhea (which is often bloody), lethargy (depression), fever, and life threatening dehydration. The wet tissue of the mouth and eyes may become noticeably red and the heart may beat too rapidly.

It has been reported from Asia, Australia, New Zealand, America and Europe. The invasion of the bone marrow cells causes a decrease in the white blood cell count leading to increased susceptibility to bacterial infections and sometimes to a shock like condition called endotoxemia. There are a variety of risk factors that can increase a dog's susceptibility to the disease. Parvovirus is extremely contagious to other dogs. Infection is generally attributed to ingestion of material contaminated by dog feces and can occur when a dog smells or licks the ground. Direct contact with another dog is not necessary for infection. Parvovirus is shed in the feces of infected dogs for approximately two weeks after initial ingestion and can live in the environment for years. There is evidence that the virus can live in ground soil for up to a year. It is resistant to most cleaning products, or even to weather changes. The virus is species specific and is not contagious to cat or humans (www. petplace.com).

Domestic and wild canines are usually affected (Nandi and Kumar, 2010). Dogs at highest risk for infection are unvaccinated puppies or those who have not yet completed their vaccine series. It is most common in puppies between 6 weeks and 6 months of age (Pollock and Coyne, 1993). Intact male dogs appear to be twice as likely to develop PV enteritis as sexually intact females (Houston et al., 1996). Unsanitary and/or overcrowded kennels may increase chance of infection and concurrent infection with parasites, other bacteria or viruses may also increase susceptibility to infection. Proper vaccination of your pet can best prevent the disease. Dogs vaccinated with over-the-counter vaccines also appear to have a higher incidence of parvovirus likely due to ineffective vaccine or improper use. Parvovirus enteritis has a survival rate of $85-90 \%$ with aggressive treatment and recovery generally occurs in 3-7 days.

The clinical signs of CPV infection can mimic many other diseases that cause vomiting and diarrhea; severe gastroenteritis in young dogs. Consequently, the diagnosis of CPV is often a challenge for the veterinarian. The positive confirmation of CPV infection requires the demonstration of the virus or virus antigen in the stool, or the detection of anti-CPV antibodies in the blood serum. The CPV - PCR has a higher sensitivity and specificity than other methods of viral antigen determination in feces (Greene and Decaro, 2012). Quantitative assays (real-time PCR) using blood can also provide an estimation of viral load, which can help distinguish vaccination from natural infection (Veir et al., 2009). Occasionally, a dog will have parvovirus but test negative for virus in the stool. Fortunately, this is an uncommon occurrence. A tentative diagnosis is often based on the presence of a reduced white blood cell count (leukopenia) and clinical signs. If further confirmation is needed, stool or blood can be submitted to a veterinary laboratory for additional tests. Some dogs that become clinically ill may not have a low white blood cell count. Sudden onset of hemorrhagic diarrhea, fever, and leukopenia in a young, unvaccinated dog is often considered indicative of CPV infection. However, not all dogs with CPV have bloody diarrhea or leukopenia, and other diseases such as parasitic or enteropathogenic bacterial infection can also cause these symptoms. Therefore, definitive diagnosis should be pursued.

The conventional methods such as clinical signs of diagnosis are being practiced in Bangladesh for the diagnosis of CPV. However these techniques have been reported to be of less diagnostic value as such there diagnostic tests may have lost of limitation for confirmatory detection of CPV infection from field and laboratory samples as well. There is only one study regarding the prevalence of CPV infection in dogs in Bangladesh (Islam et al., 2014). However, their sample size was very small (30). Therefore, the objective of this study was to estimate the prevalence of Canine Parvo Virus (CPV) inflection in street dogs using rapid antigen detection kit. 


\section{MATERIALS AND METHODS}

\section{Study period and area}

The research work was conducted in the laboratory of the Department of Medicine, Bangladesh Agricultural University, Mymensingh during the period of January 2015 to April 2015.

\section{Brief description of the experimental design}

A total of 114 rectal swab samples were collected conveniently from stray dogs of different zones (Akua, Town Hall, Amlapara, Senbari, Mintu College Road, Char Para Medical College Hospital, Boundary Road, R.K. Mission Road and Bangladesh Agricultural University, Mymensingh) of the Municipal Corporation of Mymensingh District; during the dog control programme of Municipal Corporation from January 2015 to July 2015. Rectal swab were collected before the dogs were euthanatized by the municipal authority. The dogs studied were in different ages, and mixed sexes and with no history of vaccination against canine parvo virus infection (CPV). Age, sex were recorded carefully. The age of the dog was determined by examining teeth. Health status of the dog was determined by close inspection. It was not possible to know the diarrheic status of the selected dogs.

The test was carried out with a commercial rapid RapiGEN Canine Parvo Virus (CPV) Ag Test Kit (Manufactured by RapiGEN INC. South Korea, 2004), following the manufacturer's instructions (Figure 1). The kit is a chromatographic immunoassay for the qualitative detection of canine parvo virus antigen in canine feces.

\section{Collection and processing of sample}

Rectal swab were collected from suspected dogs in the Municipal Corporation of Mymensingh District from different zones. These dogs were restrained by labors of Municipal Corporation of Mymensingh. These zones were selected because of the fact that these areas are known to be abundant of dog population. Those zones are also most exposed to wild reservoirs. After collection, samples were transferred aseptically in separate sterile plastic vial and kept in the ice carrier with icepack and then send to the laboratory of the Department of Medicine, Bangladesh Agricultural University, Mymensingh.

\section{Safety measures taken throughout the study}

All the tasks comprising of the collection of samples up to screening of CPV was performed following strict bio-security measures. Collection of samples was performed wearing personal protective equipment (PPE) like gloves, masks, apron along with proper disinfection of the clothing and other appliances. After collection the samples were transported using aseptic packaging into the laboratory.

\section{Test procedure}

Fecal samples were collected with the stick of collection device or swab. Care was taken to avoid heavy contamination of stick (swab) with extraneous material. The stick (swab) was inserted into the bottle and securely fit the top portion onto the base. Then the bottle was agitated assembly for 10 seconds by shaking vigorously to ensure good sample extraction. The test device was removed from its sealed pouch by tearing along the notch. The top of the samples were snapped into the collection device. $3-4$ drops was dispensed into the sample well(s) by squeeze and was waited for 10 minute but result was got within $5-10 \mathrm{~min}$. The test result was recorded by observing the color band by naked eye.

\section{Interpretation of the test}

Results of the tests were interpreted within 10 minutes by visual observation of single band for negative control, double band (one control and other treatment) for positive test. A color band will appear in the left section of the result window to show that the test is working properly which is known as the control band (C). The right section of the result window indicates the test results. If another color band appears in the right section of the result window, this band is the test band $(T)$. The presence of only one band within the result window indicates a negative result. The presence of two color bands ( $T$ and $C$ ) within the result window, no matter which band appears first, indicates a positive result. If the purple color band is not visible within the result window after performing the test, the result is considered invalid (Esfandiari and Klingeborn, 2000). 
Negative

One red/purple band appears in the control line(c) with no apparent band in the test line (T). The sample should be considered negative for CPV (Figure 1).

\section{Positive}

Two red/ purple bands appear. One in the control line (c) and other in the test line (T). The sample should be considered positive for CPV (Figure 2).

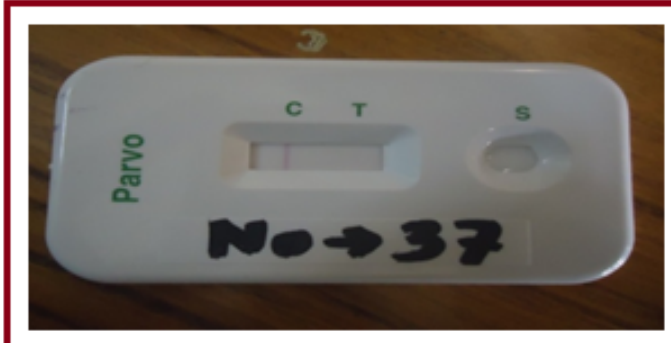

Figure 1. Negative result for CPV

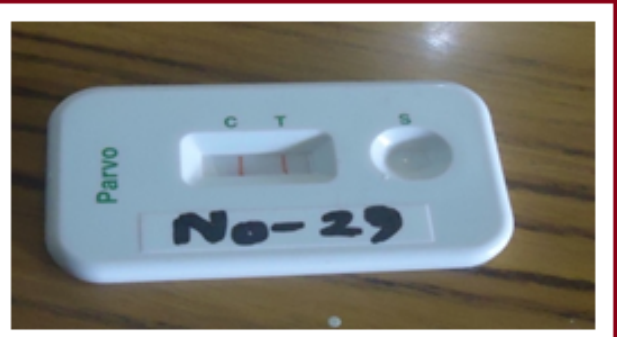

Figure 2. Positive result for CPV

\section{Invalid}

If no red/ purple band appears in the control line $(C)$ or if a band appears in the test line $(T)$ but not in the control line $(\mathrm{C})$, then the test was invalid. It was recommended to rest the specimen using a new testing device.

\section{Statistical analysis}

Chi-square test was performed using Statistical Package for Social Science (SPSS).

\section{RESULTS}

\section{Overall prevalence of Canine parvo virus infection in stray dogs}

A total 114 rectal swab was tested for the presence of CPV-2 antigen. Among them 37 samples were showed positive result. So the overall prevalence of Canine parvo virus infection in this study is $32.5 \%$ (Figure 3).

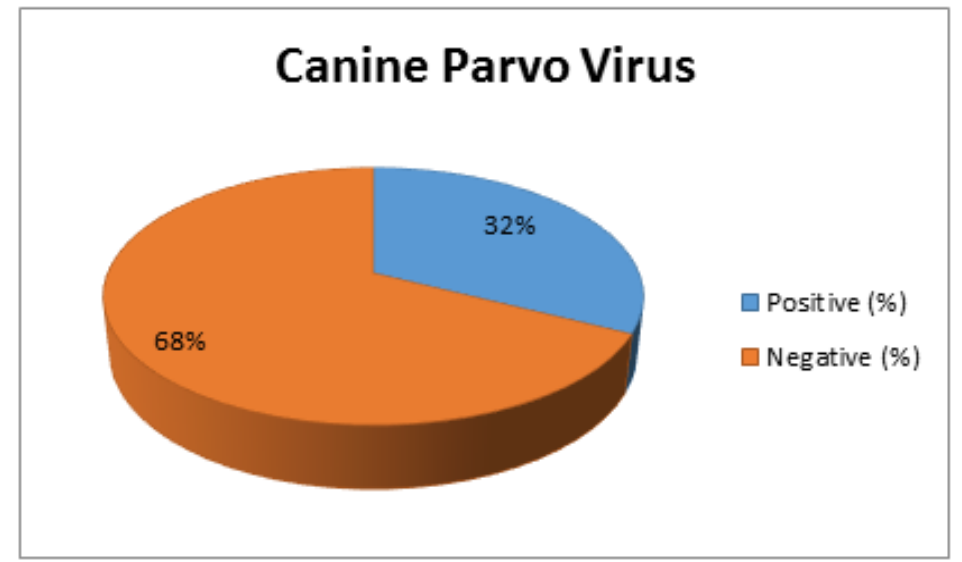

Figure 3. Overall prevalence of canine parvo virus infection in stray dogs 
Table 1. Prevalence and associated risk factors of CPV infection in Street dogs

\begin{tabular}{|c|c|c|c|c|c|}
\hline Variables & Category Level & $\begin{array}{l}\text { Number of sample } \\
\text { tested }\end{array}$ & $\begin{array}{l}\text { Number of } \\
\text { positive } \\
\text { reactors }\end{array}$ & $\begin{array}{l}\text { Percentage of positive } \\
\text { reactors }\end{array}$ & $\begin{array}{l}P- \\
\text { value }\end{array}$ \\
\hline \multirow[t]{6}{*}{ Age } & 1-6 months & 24 & 14 & $58.3 \%$ & $0.005^{*}$ \\
\hline & 7-12 months & 60 & 13 & $21.7 \%$ & * \\
\hline & $13-24$ months & 23 & 9 & $39.1 \%$ & \\
\hline & & 7 & 1 & $14.3 \%$ & \\
\hline & More than & & & & \\
\hline & 24 months & & & & \\
\hline \multirow[t]{2}{*}{ Sex } & Male & 61 & 21 & $34.4 \%$ & 0.78 \\
\hline & Female & 53 & 16 & 30.2 & \\
\hline \multirow[t]{2}{*}{ Health } & Poor & 70 & 30 & 42.85 & $0.004^{*}$ \\
\hline & Normal & 44 & 7 & 15.90 & \\
\hline \multirow[t]{11}{*}{ Area } & Town Hall & 7 & 2 & 28.56 & 0.0029 \\
\hline & Akua & 17 & 5 & 29.41 & ** \\
\hline & Boundary Road & 8 & 3 & 37.50 & \\
\hline & Amlapara & 11 & 4 & 36.36 & \\
\hline & Charpara & 4 & 0 & 00.00 & \\
\hline & Mintu College Road & 9 & 4 & 44.44 & \\
\hline & R. K. Mission Road & 25 & 8 & 32.00 & \\
\hline & Senbari Road & 13 & 3 & 23.07 & \\
\hline & Bau Campus & 20 & 8 & 40.00 & \\
\hline & Mymensingh & & & & \\
\hline & Total & 114 & 37 & $32.00 \%$ & \\
\hline
\end{tabular}

\section{Age, sex, health status and area wise prevalence of CPV infection in street dogs}

The prevalence of CPV infection was significantly higher in puppies between 1-6 months age group $(58.3 \%)$ than the other age groups and lower in older dogs more than 24 months of age $(14.3 \%)(p<0.005)$ (Table 1). Among 114 dogs, 61 were male and 53 were female and the prevalence of canine parvovirus infection in dog was $34.4 \%$ (21 out of 61 ) in male and $30.2 \%$ (16 out of 53 ) in female dogs (Table 1). However the sex wise prevalence of CPV infection was not significant statistically. The prevalence of CPV infection based on health status is shown in Table 1. The prevalence of CPV infection was significantly higher (42.85\%) in dogs with poor health status than those with normal health $(15.90)$ ( $P$-value $=0.004$ ). The area wise distribution of CPV infection is presented in (Table 1). The prevalence was higher in dogs of Mintu College Road (44.44\%) and no positive reactor was found in dogs of Charpara.

\section{DISCUSSION}

The research work was carried out to determine the prevalence of CPV infection in street dogs in Mymensingh. The prevalence of CPV infection was found to be significantly higher in puppies between 1-6 months. Similar reports were also made by Parthiban et al. (2010). There are currently a variety of methods available for the detection of CPV-2 in feces. These include hemagglutination (HA), electron microscopy (EM), polymerase chain reaction (PCR), and enzyme-linked immunosorbent assay (ELISA). Most of the test are time consuming and require specific equipment; therefore a reliable, prompt diagnostic test is necessary. There are several diagnostic methods to detect canine parvovirus infection in dog but the RapiGEN Canine Parvo Ag test is one of the most reliable and rapid one-step test based on the immunochromatographic assay of canine parvovirus antigen in canine feces.

The test requires only 5-10 minutes to complete and CPV antigen detection make this technique a useful tool for CPV diagnosis. With regard to general aspects of the test system evaluated, each of them was easy to perform and the results were easy to read. There was no invalid test result in all 114 samples. With RapiGEN Kit used as a reference test 37 positive samples (32\%) obtained by the RapiGEN canine parvovirus Ag kit 
test. If remains unclear whether this is due to carrier state. The results showed that CPV infection was a common problem in street dogs in Mymensingh. Islam et al., (2014) also reported similar prevalence of CPV infection in street dogs in Bangladesh. In the present study, the prevalence of canine parvovirus was found relatively higher in male (34.4\%) than in female (30.2\%). Similar findings were also reported by other authors (Parthiban et al., 2010 and Islam et al., 2014).

In this study, the prevalence of CPV infection in different points of Mymensingh district was varied from 0 to $44.4 \%$. Though these points are in close proximity not more than $5-8 \mathrm{~km}$ but dogs usually maintain selfterritory, it is logical that the prevalence found in the study should represent the relevant scene of whole Mymensingh. Future study should be conducted for the determination of sensitivity and specificity of the kit for wide use in field condition and for the virus isolation, serotype determination and molecular detection of the organisms.

\section{CONCLUSIONS}

Canine parvo virus infection in the street dogs of Mymensingh is highly prevalent $(32 \%)$. As the disease is preventable, so vaccination should be initiated to prevent the occurrence of disease.

\section{REFERENCES}

1. Esfandiari $\mathrm{J}$ and Klingeborn $\mathrm{B}, 2000$. A comparative study of a new rapid and one-step test for the detection of parvovirus in faeces from dogs, cats and mink. Journal of veterinary medicine. B, Infectious diseases and veterinary public health, 47: 145-153.

2. Greene CE and Decaro N, 2012. Canine viral enteritis. In: Greene CE, editor. Infectious diseases of the dog and cat. 4th ed St Louis: Elsevier, p. 67-80.

3. Houston DM, Ribble CS and Head LL, 1996. Risk factors associated with parvovirus enteritis in dogs: 283 cases (1982-1991). Journal of American Veterinary Medical Association, 208: 542-546.

4. Islam MR, Islam MA, Rahman MS, Uddin MJ, Sarker MAS, Akter L and Alam E, 2014. Prevalence of canine parvovirus infection in street dogs in Mymensingh Municipality area, Bangladesh. Microbes and Health, 3: 5-6.

5. Nandi S and Kumar M, 2010. Canine parvovirus: current perspective. Indian Journal of Virology, 21: 31-44.

6. Parthiban S, Mukhopadhyay HK, Antony PX and Pillai RM, 2010. Molecular Typing of Canine parvovirus occurring in Pondicherry by Multiplex PCR and PCR-RFLP. Indian Journal of Virology, 21: 86-89.

7. Parrish CR, 1995. Pathogenesis of feline panleukopenia virus and canine parvovirus. Baillieres Clinical Haematology, 8: 57-71.

8. Pollock RVH, and Coyne MJ, 1993. Canine Parvovirus. Veterinary Clinics of North America: Small Animal Practice, 23: 555-568.

9. Schoeman JP, Goddard A and Leisewitz AL, 2013. Biomarkers in canine parvovirus enteritis. New Zealand Veterinary Journal, 61: 217-222.

10. Shackelton LA, Parrish CR, Truyen $U$ and Holmes EC, 2005. High rate of viral evolution associated with the emergence of carnivore parvovirus. Proceedings of the National Academy of Sciences of USA, 102: 379-384.

11. Veir JK, Duffy AL, Dow SW, 2009. Comparison of quantitative PCR and conventional endpoint PCR for amplification of parvovirus DNA in blood from naturally infected and recently vaccinated dogs. Journal of Veterinary Internal Medicine, 23: 769.

12. Www.petplace.com/dogs/parvoviral-enteritis/pagel.aspx 